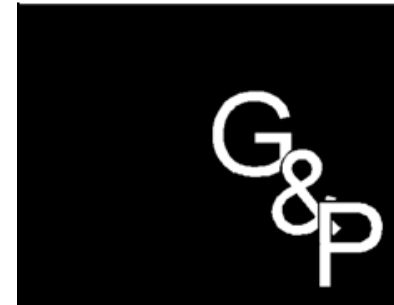

GESTÃO

$\&$

PRODUÇÃO

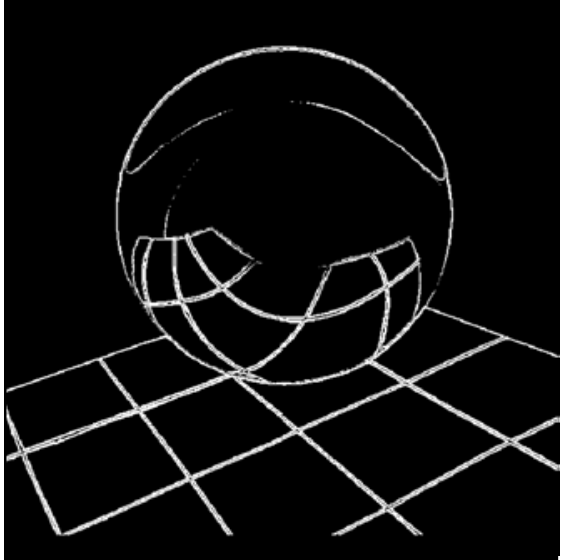

v.7, n.1, p. 1-16, abr. 2000

\section{COORDENAÇÃO VERTICAL DO TRANSPORTE DE MADEIRA: ANÁLISE EMPÍRICA DOS ARRANJOS INSTITUCIONAIS EXISTENTES NA INDÚSTRIA BRASILEIRA DE CELULOSE}

\section{Breno de Arruda Moraes Ribeiro José Vicente Caixeta Filho}

Departamento de Economia, Administração e Sociologia ESALQ/USP

E-mails: faz.sj@zaz.com.br, jvcaixet@carpa.ciagri.usp.br

\title{
Resumo
}

Este trabalho trata dos elementos que influenciam o processo de escolha dos distintos arranjos institucionais existentes no transporte de madeira entre florestas e fábricas de celulose. Buscou-se, a partir de análises estatísticas, detectar a influência das variáveis descritas pela Economia dos Custos de Transação - ECT - no processo de escolha dos arranjos institucionais. No processo de análise foram discutidas, sob a ótica dos custos de transação, não apenas as questões referentes à integração vertical, mas também aquelas referentes ao tamanho dos agentes envolvidos na transação.

Palavras-chave: integração vertical, custos de transação, indústria de celulose, transporte de madeira.

\section{Introdução}

A empresas brasileiras produtoras de celu-
entre seus reflorestamentos e fábricas de diver-
sas formas. A diferenciação destas formas de
coordenação se dá por duas características: a
primeira é a proporção da composição da frota no que se diz respeito à contratação ou realização do próprio transporte de madeira e a segunda é o tamanho da empresa transportadora a ser contratada.

As companhias do setor percorreram caminhos distintos no que se diz respeito à opção entre contratar ou realizar, elas próprias, o transporte principal. Algumas das empresas já 
iniciaram suas atividades contratando estes serviços de terceiros, sendo parte do transporte mantido sob responsabilidade da própria companhia (integração parcial). Este é, por exemplo, o caso da Klabin, que desde o início das atividades, em 1937, contratava parte dos serviços de transporte.

Outras companhias, no entanto, utilizaram no início de suas atividades o transporte próprio, passando mais tarde à terceirização parcial ou total da frota. Empresas como a Aracruz e a Jari, antes totalmente integradas, passaram a contratar serviços de terceiros a partir de 1995 e 1997, respectivamente. Apesar de realizados em períodos relativamente próximos, o processo de terceirização destas duas empresas foi distinto. A Jari optou pela terceirização parcial, contratando pequenas empresas transportadoras, enquanto a Aracruz decidiu pela terceirização total de sua frota, contratando apenas grandes transportadoras.

Este trabalho tem como objetivo analisar as diversas estratégias de coordenação vertical das empresas produtoras de celulose em relação ao transporte de madeira. Para tanto, será utilizado o arcabouço teórico da Economia dos Custos de Transação, na qual destaca-se a importância de WILLIAMSON (1991). Mais especificamente, objetiva-se: (i) descrever a transação de contratação dos serviços de transporte principal transporte de madeira entre as áreas reflorestadas e as fábricas de celulose; e (ii) buscar justificativas que expliquem tanto a diversidade do tamanho das transportadoras contratadas, como a existência de integração vertical parcial da frota.

Para alcançar os objetivos estabelecidos foi feito um trabalho de coleta de dados junto às principais empresas da indústria nacional de celulose, a partir do qual foram levantadas informações quantitativas e qualitativas que serviram tanto para caracterizar os arranjos institucionais existentes quanto para subsidiar as análises empíricas.

Além de retratar questões atuais da indústria nacional produtora de celulose, os dados coletados junto às empresas possibilitaram realizar contribuições referentes à utilização da teoria. Neste sentido destaca-se a abordagem quantitativa proposta, que utiliza variáveis proxy para medir as dimensões da transação e a utilização do modelo Forma Reduzida (modelo que associa as dimensões da transação aos arranjos institucionais) para analisar outros arranjos institucionais que não apenas aqueles relativos à integração vertical.

O trabalho está dividido em quatro seções. A primeira caracteriza as formas organizacionais utilizadas pelas principais empresas produtoras de celulose. A segunda seção descreve os procedimentos utilizados para a investigação empírica. A terceira discute os dados e apresenta os resultados obtidos e a quarta e última seção traz as considerações finais do trabalho.

\section{As Distintas Estruturas de Governança}

Os arranjos institucionais que regem a atividade de transporte de madeira são extremamente variados, sendo que as principais características destes arranjos são a integração vertical parcial, em diversas proporções, e a contratação de transportadoras de tamanhos distintos.

Dentre as empresas estudadas, três tipos de estratégias de terceirização foram identificadas como relevantes: (i) a terceirização total da frota, com a contratação de grandes empresas transportadoras (frotas superiores a 15 caminhões), (ii) a terceirização total da frota com a contratação de empresas transportadoras de médio porte (frotas entre 15 e cinco caminhões) e pequeno porte (frota inferior a 5 caminhões) e (iii) a integração vertical parcial com a contratação de pequenas empresas transportadoras. A Tabela 1 mostra as opções de terceirização feitas pelas empresas estudadas.

Segundo a ECT, a escolha entre formas organizacionais distintas é influenciada pelas três dimensões da transação (especificidade de ativos, incerteza e freqüência). Assim, espera-se que estas dimensões possam influenciar tanto a decisão pela integração parcial, quanto a escolha do número de caminhões a serem contratados por transportadora. 
Tabela 1 - Estrutura de governança dos Serviços de Transporte Principal em Janeiro de 1997. Fonte: consulta junto às empresas.

\begin{tabular}{cccc}
\hline Empresa & $\begin{array}{c}\text { Frota terceirizada } \\
(\mathbf{\%})\end{array}$ & $\begin{array}{c}\text { Frota própria } \\
(\mathbf{\%})\end{array}$ & $\begin{array}{c}\text { Número médio de veículos } \\
\text { contratados por transportadora }\end{array}$ \\
\hline A & 50 & 50 & 3 \\
B & 63 & 37 & 2 \\
C & 88 & 12 & 2 \\
D & 94 & 6 & 4 \\
E & 100 & - & 6 \\
F & 100 & - & 9 \\
G & 100 & - & 10 \\
H & 100 & - & 12 \\
I & 100 & - & 36 \\
\hline
\end{tabular}

Em relação à integração parcial, espera-se que a escolha entre esta estratégia e a terceirização total da frota esteja associada aos mesmos motivos que justificam a escolha entre integração total e terceirização. Desta forma, espera-se que ocorra integração parcial quando a empresa produtora de celulose apresentar altos níveis de especificidade de ativos e incerteza.

Quanto ao número de caminhões contratados por transportadora, espera-se que a contratação de pequenas transportadoras, ou mesmo a contratação de caminhoneiros autônomos, esteja associada a baixas especificidades e menores níveis de incerteza. Da mesma forma, espera-se que maiores níveis de especificidades e de incerteza estejam associados à contratação de um maior número de caminhões por transportadora.

Diversos elementos indicam a existência de um isomorfismo entre as relações das três dimensões da transação com as formas polares (hierarquia e mercado), e entre as relações destas mesmas dimensões e o número de caminhões contratados por transportadora, sugerindo que em situações em que maiores níveis de dependência bilateral são encontrados a contratação de grandes empresas de transporte minimiza os custos de transação existentes.

A primeira das justificativas para a existência deste isomorfismo reside no fato de que a integração vertical total pode ser vista como um contrato entre a empresa de celulose e seu departamento de transporte, ou seja, o transporte de madeira estaria, neste caso, sob a responsabilidade de apenas uma grande transportadora, cujos proprietários são os mesmos da empresa de celulose. Assim, a integração vertical estaria associada à contratação de grandes empresas transportadoras.

Outra evidência deste isomorfismo está no fato de que as negociações com empresas de grande porte são, geralmente, baseadas em planilhas de custos, e não apenas nos preços de mercado dos fretes rodoviários, como acontece nas negociações com os caminhoneiros autônomos. Assim, mesmo sendo contratadas no mercado, as grandes empresas transportadoras não têm a continuidade de seus contratos vinculada exclusivamente aos preços de mercado. Neste caso, são também considerados nas negociações os custos operacionais, o que torna o relacionamento da companhia de celulose com a transportadora similar ao relacionamento mantido com os demais departamentos da companhia.

Também em relação à negociação, é interessante ressaltar que o grau de dependência entre a empresa produtora de celulose e as grandes transportadoras é maior, uma vez que em caso de desacordo, os custos advindos do desabastecimento da fábrica são proporcionais à porcentagem do abastecimento destinado à transportadora em questão. No caso de contratação de caminhoneiros autônomos, por exemplo, o não cumprimento 
de um contrato por parte do transportador implica pequenas perdas (ou mesmo nenhuma perda, caso a frota utilizada trabalhe com capacidade de transporte superior ao necessário). Assim, da mesma forma que as estruturas de mercado e hierarquia apresentam níveis distintos de dependência bilateral, espera-se que, comparada à contratação de grandes empresas transportadoras, a contratação de pequenas transportadoras esteja associada a menores níveis de dependência bilateral.

Assumindo que as relações propostas pela ECT para escolhas entre hierarquia e mercado possam ser estendidas tanto para as escolhas entre grandes e pequenas transportadoras, quanto para as escolhas entre integração parcial e terceirização total, foi conduzida uma pesquisa empírica para obter os dados exigidos pelo modelo Forma Reduzida. Esta pesquisa é apresentada na seção seguinte.

\section{Material e Método}

A $\mathrm{s}$ informações utilizadas têm origem de três fontes distintas: entrevistas, questionários e relatórios gerados pelas organizações de classe. As entrevistas e questionários abrangem 9 das 12 maiores empresas do setor. As empresas representadas neste estudo e suas participações na produção nacional de pastas químicas e semiquímicas (celulose) no ano de 1995 são apresentadas na Tabela 2.

As informações coletadas a partir de questionário têm como função caracterizar as formas organizacionais utilizadas, e medir as variáveis denominadas "dimensões da transação": especificidade locacional; especificidade de ativo dedicado; especificidade de ativo físico; especificidade temporal; incerteza e freqüência. Estes atributos foram medidos da seguinte forma:

\section{a) Especificidade locacional e de ativos dedicados}

A especificidade locacional associada ao transporte principal diz respeito à necessidade de que as transportadoras estejam situadas próximas ao trajeto entre a fábrica de celulose $\mathrm{e}$ as florestas. Esta proximidade geográfica visa a redução de custos com transporte, pois reduz a distância entre o local de origem do caminhão a garagem da transportadora - e o local de trabalho do veículo - o trajeto entre fábrica e florestas. Em outras palavras, por permitir a prática de fretes mais baixos, devido à proximidade geográfica, a contratação de serviços de uma determinada transportadora está associada a uma maior especificidade locacional.

No caso das companhias de celulose estudadas, $62 \%$ dos 765 caminhões contratados pertencem a transportadoras cujas garagens estão localizadas próximas às fábricas (dentro de um raio de $20 \mathrm{~km}$ ) e $15 \%$ próximas às florestas (não foi possível determinar a localização dos demais $23 \%$ dos caminhões).

A presença de ativos dedicados diz respeito a investimentos realizados por um fornecedor visando atender à demanda de um cliente específico. No caso do término prematuro do contrato o fornecedor ficaria com um excesso de capacidade significativo. Para a atividade de transporte de madeira, o investimento em questão geralmente diz respeito à aquisição de caminhões e à instalação de uma base operacional próxima à fábrica ou às florestas.

Os fatos apresentados indicam que a caracterização tanto da especificidade locacional quanto da especificidade de ativos dedicados pode ser realizada a partir do mercado regional de fretes. Isso porque, no caso da especificidade locacional, estando fixado o fato de haver a necessidade de relacionamento cara a cara, deve-se analisar a questão da realocação dos ativos em questão.

No caso da especificidade de ativos dedicados, havendo quebra contratual o mercado regional determinará a necessidade de investimentos específicos, seja para as empresas produtoras de celulose (caso haja a dificuldade de contratação de outras transportadoras), seja para a transportadora (caso haja dificuldade de realocação dos caminhões).

A mensuração das especificidades de ativos dedicados e locacional pode, então, ser feita por uma mesma variável. Esta variável deve 
Tabela 2 - Participação das Empresas Estudadas na Produção Nacional de Pastas Químicas e Semiquímicas no ano de 1995.

Fonte: ANFPC (1995)

\begin{tabular}{ccccc}
\hline Ranking & Empresa & Estado & $\begin{array}{c}\text { Produção de } \\
\text { Celulose (t) }\end{array}$ & $\%$ \\
\hline 1 & I & ES & 1.041 .765 & 19 \\
2 & E & SP & 493.300 & 9 \\
4 & B & PR & 418.939 & 8 \\
7 & C & SP & 306.170 & 6 \\
8 & H & SP & 266.460 & 5 \\
9 & F & SC & 263.021 & 5 \\
10 & A & PA & 256.266 & 5 \\
11 & G & RS & 252.410 & 5 \\
12 & D & SC & 169.099 & 3 \\
Subtotal & & & 3.467 .430 & 65 \\
Outros & & & 1.919 .401 & 35 \\
TOTAL & & & 5.386 .831 & 100 \\
\hline
\end{tabular}

considerar a proporção entre o número de caminhões demandados pela empresa produtora de celulose e o número de caminhões disponíveis no mercado, similarmente ao proposto por JOSKOW (1987).

Dadas as dificuldades em determinar o número de caminhões em uma dada região, será utilizada como proxy para esta variável o valor da produção industrial na região de contratação dos caminhões (municípios ao redor da fábrica ou das florestas), pois espera-se que em regiões onde a produção industrial seja maior deva haver uma maior oferta de serviços de transporte.

Os municípios para os quais a produção industrial será considerada serão aqueles localizados dentro de um raio de $20 \mathrm{~km}$ do município de referência para a contratação. Assim, o valor da especificidade de ativos dedicados e locacional será dado pela razão entre o número de caminhões demandados pela fábrica e o valor da produção industrial da região de contratação.

\section{b) Especificidade de ativo físico}

$\mathrm{O}$ transporte de madeira para a fabricação de celulose exige a utilização de carretas especificamente desenhadas para esta atividade. Tais carretas podem ser obtidas tanto pela adaptação das carretas comuns de transporte geral quanto pela aquisição de carretas especificamente planejadas para o transporte florestal. Em ambos os casos existe a necessidade de investimentos que não são reempregáveis em outras atividades, implicando perda de valor do ativo caso haja rompimento de contrato.

A existência de especificidade de ativos físicos foi utilizada por MONTEVERDE \& TEECE (1982), citado por MAHONEY et al. (1994), na avaliação da integração para trás das montadoras Ford e GM com seus fornecedores. Neste estudo os autores utilizaram como proxy para a medida de especificidade de ativo físico o fato das peças serem ou não produzidas para uma única montadora.

No transporte principal a carreta pode prestar serviços para outras empresas que consomem madeira, sejam elas empresas produtoras de celulose ou não. Desta forma, a existência de especificidade de ativo físico será medida por uma variável tipo dummy. A especificidade será considerada relativamente menor caso a empresa transportadora preste serviços para outras empresas florestais. Caso contrário, esta 
especificidade será considera relativamente maior.

\section{c) Especificidade temporal}

A especificidade temporal presente no transporte principal está associada ao processo contínuo de produção, pois a não ocorrência da transação, em um dado momento, pode implicar a paralisação da planta e os conseqüentes custos associados a esta paralisação.

Os custos advindos de uma interrupção brusca do fornecimento de serviços de transporte são proporcionais ao período de tempo necessário para que uma nova transportadora comece a trabalhar e ao tamanho da transportadora em questão. Caso esta contratação seja rápida e a transportadora pequena em relação ao total da frota utilizada, os custos de desabastecimento serão pequenos, assim como a especificidade temporal associada.

Portanto, a especificidade temporal poderá ser medida pelo tempo de espera para a contratação de uma nova transportadora ponderado pelo percentual médio do abastecimento sob responsabilidade de cada transportadora.

\section{d) Incerteza}

A incerteza presente na contratação de serviços de transporte de madeira está associada à dificuldade em se ajustar de forma eficiente a oferta de serviços de transporte e a demanda da fábrica por madeira. Em períodos cuja demanda por celulose cresce repentinamente, as empresas produtoras de celulose podem encontrar dificuldades para contratar caminhões.

MAHONEY et al. (1994) descrevem as variáveis utilizadas como medida para incerteza para diversos trabalhos que utilizam a ECT como arcabouço teórico. Nestes destacam-se tanto a utilização de variações nos volumes comercializados, quanto as diferenças entre quantidades comercializadas e previstas.

A dificuldade de adaptações eficientes às diferenças entre oferta e demanda por serviços de transporte aumenta a importância da opção por formas organizacionais menos suscetíveis a incertezas. Neste caso, considera-se também como incerteza os problemas comumente denominados como riscos, ou seja, variações previsíveis que podem ser descritas por meio de funções distribuição de probabilidade, como por exemplo as variações sazonais inerentes à atividade.

A incerteza presente no transporte de madeira será estimada a partir da oscilação do número de caminhões demandados pelas empresas de celulose. Esta oscilação tem duas origens principais: a quantidade de madeira transportada e a distância média percorrida. A partir destas duas informações, e de outros dados operacionais, pode-se estimar o número de caminhões demandados. Entretanto, devido às dificuldades em se obter dados com nível de detalhamento exigido para esta simulação, optou-se por utilizar apenas a quantidade transportada como proxy para o número de caminhões demandados pela empresa produtora de celulose. Desta forma, a incerteza será medida pelas oscilações nas quantidades transportadas de madeira.

\section{e) Freqüência}

A freqüência de ocorrência da transação será considerada constante para todas as empresas, pois o processo produtivo exige abastecimento contínuo das fábricas. Este pressuposto não representa uma simplificação excessiva da realidade, pois as alterações na freqüência estão sendo consideradas por meio da variável incerteza.

\section{Análise dos Dados}

$\mathrm{C}$ onforme colocado no início deste trabalho, existem duas características básicas que diferenciam as formas organizacionais adotadas pelas empresas produtoras de celulose para a coordenação dos serviços de transporte de madeira: a primeira é a opção pela terceirização total ou pela integração vertical parcial e a segunda diz respeito à escolha do número de caminhões contratados por transportadora. Estas características serão analisadas nas subseções seguintes. 


\subsection{Análise do Grau de Terceirização do Transporte Principal}

A análise da influência das variáveis estudadas sobre a opção da empresa pela integração parcial ou terceirização total não pôde ser feita a partir de uma regressão linear simples, pois a variável dependente é binária. Também a utilização de modelos do tipo probit e logit foi descartada devido ao número reduzido de observações. Assim sendo, optou-se pela utilização de testes não paramétricos para analisar os dados obtidos.

O teste realizado foi o Teste Exato de Fisher. Segundo SIEGEL (1956, p.96), esta é "uma técnica não paramétrica extremamente útil para analisar dados discretos, quando o tamanho das duas amostras independentes é pequeno."

O Teste Exato de Fisher foi utilizado para verificar se as magnitudes das especificidades calculadas estavam ou não correlacionadas com a opção pela integração parcial ou pela terceirização total. O teste considera duas possibilidades: a) $\mathrm{H}_{0}$ - Tanto as empresas que trabalham com frotas totalmente terceirizadas quanto as que apresentam integração parcial da frota estão associadas a valores médios similares de especificidades; b) $\mathrm{H}_{1}$ - Empresas que trabalham com frotas totalmente terceirizadas apresentam valores médios de especificidades menores em relação aos daquelas que mantêm ao menos parte de sua frota integrada verticalmente.

Os valores das variáveis analisadas e os critérios de divisão das variáveis dependentes são mostrados na Tabela 3. Nesta, DEDICADOS representa os valores estimados para a especificidade de ativos dedicados e locacional; a variável TEMPORAL representa a especificidade temporal existente na transação; FÍSICO considera a presença de especificidade de ativos físicos; e INCERTEZA é a variável que considera a incerteza presente na transação.

O resultado do Teste de Fisher para a variável DEDICADOS foi maior que o nível de significância adotado $(0,05)$. A probabilidade de ocorrência da situação verificada sob $\mathrm{H}_{0}$ é igual a 0,32 , ou seja, não é possível rejeitar a hipótese de que empresas que trabalham com frotas totalmente terceirizadas, bem como empresas que apresentam integração parcial da frota estão associadas a valores médios similares de especificidade de ativos dedicados e locacional.

Conforme mostrado na Tabela 4, os testes para as demais variáveis também mostraram-se não significativos, ou seja, não foi possível identificar diferenças significativas entre os valores das especificidades dos dois grupos de empresas.

Ao contrário do que se esperava, a integração parcial não apresentou correlação explícita com altos valores de especificidade de ativos ou incerteza.

A falta de significância dos testes realizados nos leva a considerar possíveis falhas na análise dos dados. Dois motivos principais podem implicar erro. O primeiro diz respeito à impossibilidade de se considerar a inter-relação entre as diversas variáveis que compõem as dimensões da transação, pois estas são avaliadas uma a uma e não em conjunto. $O$ segundo motivo diz respeito ao número limitado de formas organizacionais que estão sendo consideradas apenas duas (integração parcial e terceirização total), enquanto na realidade existe uma série de nuanças que distinguem formas que, em princípio, são consideradas iguais.

Um terceiro motivo pode justificar a baixa correlação entre altos índices de especificidade e a opção pela integração vertical parcial. É possível que outros fatores, além da busca de economias em custos de transação, influenciem esta escolha.

AZEVEDO (1996) destaca que a integração parcial pode surgir não apenas como uma forma eficiente de estrutura de governança, mas também como instrumento estratégico de barganha. Este argumento é compatível com as declarações de algumas empresas produtoras de celulose, para as quais a integração parcial busca garantir parte do abastecimento no caso de rompimento de contrato com alguma transportadora. 
Tabela 3 - Grau de terceirização das frotas em relação às especificidades estimadas. Fonte: dados da pesquisa.

\begin{tabular}{cccccc}
\hline Empresa & Terceirização & Dedicados & Temporal & Físico* $^{*}$ & Incerteza \\
\hline A & $50 \%$ & 3,38 & 2,17 & 1 & - \\
B & $63 \%$ & 3,7 & 0,58 & 0 & $6 \%$ \\
C & $88 \%$ & 0,9 & 0,15 & 1 & $5 \%$ \\
D & $94 \%$ & 7,7 & - & 0 & $6 \%$ \\
I & $100 \%$ & 10,9 & 11,25 & 1 & $7 \%$ \\
E & $100 \%$ & 0,8 & 0,83 & 1 & $4 \%$ \\
H & $100 \%$ & 0,2 & 0,00 & 1 & - \\
F & $100 \%$ & 6,2 & 1,50 & 0 & $19 \%$ \\
G & $100 \%$ & 0,4 & 0,33 & 0 & $6 \%$ \\
\hline Critério & - & 1 & 1 & - & $6,5 \%$ \\
\hline
\end{tabular}

* O número 1 significa que a transportadora presta serviços para outras empresas florestais, enquanto o número 0 significa que a transportadora não presta serviços para outras empresas florestais

Tabela 4 - Resultados do Teste Exato de Fisher. Fonte: dados da pesquisa.

\begin{tabular}{lc}
\hline \multicolumn{1}{c}{ Variáveis } & Resultados do Teste Exato de Fisher \\
\hline DEDICADOS & 0,32 \\
TEMPORAL & 0,53 \\
FÍSICO & 0,47 \\
INCERTEZA & 0,29 \\
\hline
\end{tabular}

Para as três empresas nas quais a integração parcial é relevante (Empresa A, Empresa B e Empresa C), destaca-se o fato de que todas elas contratam pequenas empresas transportadoras, situação em que uma parcela da frota que é integrada pode substituir uma transportadora em caso de quebra contratual. Tal fato nos permite inferir que, do ponto de vista da empresa produtora de celulose, a integração parcial pode ser considerada um instrumento de barganha eficiente apenas para os casos de contratação de pequenas transportadoras.

De fato, dentre as variáveis consideradas, apenas o número médio de caminhões contratados por empresa transportadora (NUMCAM) apresentou correlação com a escolha entre terceirização total ou integração parcial. $\mathrm{O}$ resultado do Teste Exato de Fisher mostrou-se altamente significativo, sendo que a probabilida- de de ocorrência da situação observada sob $\mathrm{H}_{0}$ é de 0,005. Ou seja, pode-se concluir que empresas com frotas totalmente terceirizadas diferem das empresas com frotas parcialmente integradas no que se diz respeito ao tamanho das transportadoras contratadas.

Buscando aprofundar o entendimento das características que influenciam a escolha entre diferentes formas organizacionais, foi feita uma análise que correlaciona o número médio de caminhões contratados por empresa transportadora (NUMCAM) e as dimensões da transação. Esta análise é apresentada na seção seguinte.

\subsection{Análise do Número de Caminhões Con- tratados por Empresa Transportadora}

Dentre as variáveis presentes no modelo da forma reduzida, as identificadas como relevantes 
para este estudo são as seguintes: especificidade de ativo dedicado, especificidade temporal, especificidade de ativo físico e incerteza. A análise proposta nesta seção considera que estas variáveis influenciam a escolha do número de caminhões contratados por transportadora da mesma forma que influenciam a escolha entre as formas organizacionais de mercado e hierarquia.

A escolha do número de caminhões contratados por transportadora revelou-se uma das principais características que distingue as empresas que optaram por integração parcial ou terceirização total.

De fato, a variável denominada NUMCAM mostrou-se útil para superar grande parte dos problemas enfrentados na seção anterior. Em primeiro lugar, o número de caminhões contratados por transportadora serve para melhor caracterizar o arranjo institucional adotado, pois está intimamente associado à forma de negociação utilizada. De forma genérica verificou-se que a contratação de um grande número de caminhões por transportadora está associada a contratos formais e negociação de preços mediante planilhas de custos, como é o caso da Empresa I. Já a contratação de um pequeno número de caminhões por transportadora está associada à não necessidade de contratos formais e à negociação com base nos preços de mercado, como é o caso da Empresa E e da Empresa C.

Assim, a consideração desta característica resolve o problema apresentado na seção anterior, na qual empresas como a Empresa I e a Empresa E eram consideradas como pertencentes a um mesmo grupo - empresas com serviços de transporte totalmente terceirizados - mesmo diferindo consideravelmente em relação à forma com que negociam com suas transportadoras.

Além de melhor caracterizar o arranjo institucional adotado e também pelo fato de se tratar de uma variável contínua, a análise do número de caminhões contratados por transportadora amplia a gama de ferramentas disponíveis para a análise dos dados, possibilitando, inclusive, a análise conjunta das variáveis determinantes dos custos de transação.
Por fim, a variável NUMCAM representa por si só um parâmetro para discussão sobre o poder de barganha, tanto das transportadoras, quanto da empresa produtora de celulose, possibilitando que se considere a influência da busca por uma melhor posição no processo de barganha como sendo uma das características determinantes da escolha do arranjo institucional.

Para a empresa produtora de celulose, uma boa posição no processo de barganha estaria garantida caso esta pudesse substituir uma transportadora sem que seu abastecimento de madeira fosse afetado. Assim, espera-se que a empresa produtora de celulose obtenha maiores benefícios no processo de barganha caso a parcela do abastecimento a ser negociada com cada transportadora seja a menor possível.

Sob a ótica da ECT, espera-se que a contratação de um pequeno número de caminhões por transportadora esteja associada a menores níveis de dependência e, portanto, menores níveis de especificidade. Da mesma foram, espera-se que a contratação de um grande número de caminhões por transportadora esteja associada a maiores níveis de dependência e, por sua vez, a maiores níveis de especificidade.

Assim, a empresa produtora de celulose contratará um grande número de caminhões por transportadora $(\mathrm{N})$, ou seja, contratará grandes transportadoras, caso os custos de transação (C) associados a esta contratação sejam menores que os custos de transação (c) associados à contratação de um pequeno número de caminhões por transportadora (n) - pequenas transportadoras ou caminhoneiros autônomos. Utilizando a mesma notação de MASTEN (1994), temos que a escolha do "número eficiente" de caminhões $\left(G^{*}\right)$ pode ser representada da seguinte forma:

$$
G^{*}=\left\{\begin{array}{l}
\mathrm{N}, \text { se } \mathrm{c}>\mathrm{C}, \\
\mathrm{n}, \sec <\mathrm{C},
\end{array}\right.
$$

Para verificar a validade desta proposta foi feita a associação direta do número de caminhões contratados por transportadora às dimensões observáveis da transação. 
Devido à existência de restrição quanto ao número de observações disponíveis, e também considerando o fato de que existe um amplo espectro de opções - tamanhos de transportadoras - ao invés de se utilizar o modelo proposto por MASTEN (1994, p.4), buscou-se associar, pelo método dos mínimos quadrados, as dimensões observáveis da transação $(\mathrm{X})$ ao número médio de caminhões contratados por transportadora (NC), utilizando-se o seguinte modelo:

$$
\mathrm{NC}=\beta \mathrm{X}+\varepsilon,
$$

Mais especificamente, o modelo proposto busca, pela inclusão das variáveis consideradas relevantes, detectar as influências das dimensões da transação sobre o número médio de caminhões contratados de cada uma das transportadoras envolvidas no abastecimento da fábrica. A saber:

$$
\begin{aligned}
\text { NUMCAM }= & \alpha+\beta_{1} \text { DEDICADOS }+ \\
& +\beta_{2} \text { FÍSICO }+ \\
& +\beta_{3} \text { INCERTEZA }+\varepsilon,
\end{aligned}
$$

Entretanto, mesmo a utilização deste modelo é limitada pelo pequeno número de observações disponíveis, o que exige a consideração de duas restrições. A primeira delas diz respeito ao pressuposto de que os erros cometidos ( $(\varepsilon)$ observam uma distribuição normal. Não sendo possível assumir a normalidade dos erros, os parâmetros estimados não podem ter sua confiabilidade estimada pelos testes estatísticos.

$\mathrm{O}$ segundo problema relacionado ao número restrito de observações diz respeito à impossibilidade de utilização de um número grande de variáveis independentes. Quanto mais variáveis independentes forem utilizadas simultaneamente, menor será o número de graus de liberdade da regressão. Para contornar este problema, um pequeno número de variáveis independentes deverá ser analisada de cada vez.

As restrições mencionadas, associadas à existência de alta correlação entre as variáveis explicativas, frustrou a realização de uma regressão com todas variáveis relevantes. Buscando superar tal problema, optou-se por eliminar a variável TEMPORAL, uma vez que a regressão que considera a variável DEDICADOS mostrouse mais adequada.

Apesar dos parâmetros encontrados para a variável DEDICADOS e FÍSICO serem positivos, como esperado, os resultados obtidos não foram considerados confiáveis, devido aos problemas já mencionados. Também o sinal negativo estimado para a variável incerteza não é compatível com o esperado, provavelmente devido à qualidade das informações coletadas. Portanto, optou-se por realizar uma análise mais detalhada da influência das variáveis estimadas sobre o número médio de caminhões contratados, analisando-se uma a uma a relação entre as variáveis independentes e dependente. Os parâmetros obtidos são mostrados na Tabela 5.

\section{a) Especificidade de ativos dedicados}

Em relação à especificidade de ativos dedicados, espera-se que quanto maiores forem os valores apresentados por esta variável (DEDICADOS), maior será o tamanho médio das transportadoras contratadas. Isso porque, em regiões cuja demanda de transporte da empresa produtora de celulose represente uma parcela considerável do mercado de fretes local, os investimentos necessários para suprir tal demanda serão grandes, exigindo, muitas vezes, a contratação de firmas com grande capacidade de investimento.

Espera-se que seja mais fácil para a empresa produtora de celulose contratar um grande número de caminhões em uma única negociação do que fomentar a ampliação da frota de pequenas transportadoras ou mesmo de caminhoneiros autônomos.

Além da facilidade de negociação, espera-se que dada a existência de investimentos idiossincráticos feitos pelas grandes transportadoras, estas tenham maior interesse em manter relacionamentos de longo prazo, reduzindo os riscos de rompimento de contrato e o conseqüente desabastecimento da fábrica. Da mesma forma, pequenas transportadoras, por não realizarem 
Tabela 5 - Parâmetros estimados.

Fonte: dados da pesquisa.

\begin{tabular}{lccc}
\hline \multicolumn{1}{c}{ Variável } & Parâmetro & Parâmetro Estimado & Teste t \\
\hline Intercepto & $\alpha$ & $-0,26$ & 0,98 \\
DEDICADO & $\beta_{1}$ & 1,74 & 0,31 \\
FÍSICO & $\beta_{2}$ & 12,14 & 0,35 \\
INCERTEZA & $\beta_{3}$ & $-0,08$ & 0,93 \\
\hline
\end{tabular}

investimentos específicos para uma transação específica, implicam maior probabilidade de rompimento de contrato.

Os dados apresentados na Tabela 6 foram classificados de acordo com os valores calculados para a especificidade de ativos dedicados. A regressão linear destes valores em relação ao número médio de caminhões apresentou um $\mathrm{R}^{2}$ de 0,32 , com um nível de significância de $10 \%$. Estes números podem ser considerados satisfatórios, levando-se em conta que apenas uma variável dependente foi utilizada.

Como era esperado, o parâmetro obtido foi positivo $(1,72)$. Para as empresas cujos valores estimados para a especificidade de ativos dedicados são relativamente mais altos, foi verificado um número maior de caminhões por transportadora. É o caso da Empresa I, Empresa D e Empresa F.

Da mesma forma, empresas cujas transportadoras contratadas são de pequeno porte apresentaram valores mais baixos de especificidade de ativos dedicados e locacional, a exemplo das empresas Empresa B, Empresa C e Empresa A.

Todavia, a análise dos dados por empresa indica que para baixos valores de especificidade de ativos dedicados e locacional, a relação esperada não é necessariamente observada. Empresas como a Empresa H, Empresa G e Empresa E, apesar de apresentarem baixos valores de especificidade de ativos dedicados e locacional $(0,25,0,38$, e 1,26 , respectivamente) contratam transportadoras de médio porte $(12,10$ e 6 caminhões). Este fato indica que para valores elevados desta especificidade existem restrições à contratação de transportadoras de pequeno porte. Entretanto, baixos valores de especificidade de ativos dedicados e locacional não restringem a contratação de grandes transportadoras.

\section{b) Especificidade temporal}

A especificidade temporal está associada diretamente aos custos decorrentes da não realização de uma transação em um determinado momento. Assim, é razoável esperar que tais custos sejam proporcionais ao "volume de transação em questão" e ao intervalo de tempo durante o qual a transação é postergada.

Neste estudo, o "volume de transação" é a proporção do abastecimento da fábrica destinada a cada transportadora, enquanto o tempo durante o qual a transação é postergada corresponde à expectativa de demora para a contratação de uma nova transportadora. Portanto, espera-se que a contratação de um maior número de caminhões por transportadora esteja associada a maiores níveis de especificidade, seja por responderem por uma maior proporção do abastecimento da fábrica, seja por estarem associadas a um processo de contratação mais complexo.

O parâmetro obtido para a regressão entre os valores estimados para a especificidade temporal e o número médio de caminhões por transportadora foi positivo $(2,69)$, apresentou um elevado índice $\mathrm{R}^{2}(0,80)$ e um excelente nível de significância (1\%).

Os valores encontrados para a especificidade temporal, mostrados na Tabela 7, são bastante irregulares. Empresas como a Empresa I, Empresa $\mathrm{F}$ e Empresa $\mathrm{E}$, apresentaram valores relativamente maiores que aqueles obtidos para a Empresa B e Empresa C, confirmando as expec- 
Tabela 6 - Caracterização da especificidade de ativos dedicados e locacional.

Fonte: dados da pesquisa.

\begin{tabular}{ccccc}
\hline Empresa & $\begin{array}{c}\text { Produção industrial, } \\
\text { 1985 (em milhares de } \\
\text { Cruzeiros) - A }\end{array}$ & $\begin{array}{c}\text { Número total de } \\
\text { caminhões } \\
\text { contratados - B }\end{array}$ & $\begin{array}{c}\text { Especificidade de } \\
\text { ativos dedicados e } \\
\text { locacional - } \\
\text { (B/A)*100.000 }\end{array}$ & $\begin{array}{c}\text { Número médio de } \\
\text { caminhões por } \\
\text { transportadora }\end{array}$ \\
\hline I & 1.439 .961 .714 & 145 & 10,07 & 36,3 \\
D & 822.683 .850 & 66 & 8,02 & 5,3 \\
F & 1.617 .430 .204 & 94 & 5,81 & 9,4 \\
B & 1.341 .850 .937 & 49 & 3,65 & 1,6 \\
A & 887.300 .328 & 30 & 3,38 & 2,6 \\
C & 9.102 .636 .187 & 80 & 0,88 & 1,6 \\
E & 6.254 .266 .327 & 77 & 1,23 & 6,4 \\
G & 24.756 .345 .975 & 94 & 0,38 & 10,4 \\
H & 52.978 .051 .288 & 132 & 0,25 & 12,0 \\
\hline Média & 11.022 .280 .757 & 85 & 3,74 & 9,5 \\
\hline
\end{tabular}

Tabela 7- Caracterização da especificidade temporal. Fonte: dados da pesquisa.

\begin{tabular}{|c|c|c|c|c|}
\hline Empresa & $\begin{array}{c}\text { Participação média } \\
\text { das transportadoras } \\
\text { no abastecimento da } \\
\text { fábrica - (A) }\end{array}$ & $\begin{array}{c}\text { Tempo médio de espera } \\
\text { (dias) para a contratação } \\
\text { de uma nova } \\
\text { transportadora - (B) }\end{array}$ & $\begin{array}{c}\text { Especificidade } \\
\text { temporal - } \\
\left(\mathrm{A}^{*} \mathrm{~B}\right)\end{array}$ & $\begin{array}{l}\text { Número médio de } \\
\text { caminhões por } \\
\text { transportadora }\end{array}$ \\
\hline I & $25 \%$ & 45,0 & 11,25 & 36,3 \\
\hline A & $9 \%$ & 25,0 & 2,17 & 2,6 \\
\hline $\mathrm{F}$ & $10 \%$ & 15,0 & 1,50 & 9,4 \\
\hline E & $8 \%$ & 10,0 & 0,83 & 6,4 \\
\hline B & $3 \%$ & 17,5 & 0,58 & 1,6 \\
\hline G & $11 \%$ & 3,0 & 0,33 & 10,4 \\
\hline $\mathrm{C}$ & $2 \%$ & 7,5 & 0,15 & 1,6 \\
\hline $\mathrm{H}$ & $9 \%$ & 0,0 & 0,0 & 12,0 \\
\hline $\mathrm{D}^{*}$ & $8 \%$ & - & - & 5,3 \\
\hline Média & $9 \%$ & 15,38 & 2,10 & 9,51 \\
\hline
\end{tabular}

* Dados não disponíveis para esta empresa.

tativas; entretanto, a relação esperada não foi observada para as empresas Empresa G, Empresa $\mathrm{H}$ e Empresa A. Assim como para a especificidade de ativos dedicados, as duas primeiras empresas, apesar de apresentarem baixos valores para a especificidade, contratam um número de caminhões por transportadora acima da média, indicando que baixos valores de especificidade temporal não implicam necessariamente a contratação de pequenas transportadoras.

Tanto para a Empresa H, quanto para a Empresa $\mathrm{G}$, os baixos níveis de especificidade temporal estão associados à facilidade que estas empresas têm em realizar a contratação de uma nova transportadora no caso de rompimento de contrato. Esta facilidade de contratação é 
confirmada pelo baixo valor de especificidade locacional, a qual indica que ambas as empresas estão localizadas em regiões com boa oferta de serviços de transporte.

\section{c) Especificidade de ativo físico}

A análise estatística da especificidade de ativos físicos ficou comprometida pelo fato da única variável independente assumir valores binários. Todavia, a Tabela 8 indica não existir correlação entre o número de caminhões contratados por transportadora e o fato delas realizarem ou não transporte de madeira para outras empresas.

Dado o fato da variável FÍSICO ser discreta, foi realizado o Teste de Fisher para verificar se existe correlação entre esta variável e o número médio de caminhões contratados por transportadora (NUMCAM). Apesar de não apresentar relação direta com o número de caminhões contratados, a especificidade de ativo físico permite uma leitura interessante quando relacionada com as variações dos números de caminhões contratados.

Em caso de rompimento de contrato ou dispensa de caminhões devido a oscilações na demanda de serviços de transporte de madeira, as transportadoras que prestam serviços para diversas empresas florestais poderão realocar suas carretas sem maiores custos. Já para as transportadoras que trabalham para uma única empresa florestal, esta realocação exigirá investimentos para a adaptação das carretas para o transporte de carga geral. Assim, é razoável esperar que seja mais fácil para as empresas que contratam transportadoras que já trabalham com transporte de madeira ajustar o número de caminhões contratados às oscilações na demanda por transporte de madeira.

De fato, a Tabela 9 mostra que quando indagadas sobre variações na quantidade de caminhões contratados, apenas as empresas cujas transportadoras trabalham para outras empresas florestais (Empresa I, Empresa $\mathrm{H}$ e Empresa E) responderam que alteram as quantidades de caminhões contratados ao longo do ano. Isto indica que as companhias que estão associadas a uma menor especificidade de ativos físicos são capazes de melhor ajustar o número de caminhões efetivamente demandados e contratados.

É interessante ressaltar que estas companhias não contratam transportadoras de pequeno porte, o que sugere que a contratação de transportadoras deste porte não contribui para um melhor ajustamento entre o número de caminhões demandados e contratados.

\section{d) Incerteza}

A incerteza foi uma das variáveis mais prejudicadas na coleta de dados, uma vez que em alguns casos, as informações necessárias para calcular a variância das quantidades de madeira transportadas ou não foram fornecidas, ou foram fornecidas apenas para os primeiros quatro meses de 1997.

Os dados relativos às alterações no número de caminhões contratados é um segundo conjunto de informações que pode trazer esclarecimentos acerca da influência da incerteza presente na transação estudada. Apesar de não apresentarem correlação com o tamanho das empresas contratadas, as variáveis INCERTEZA e FÍSICO, geram uma análise interessante quando relacionadas a estas informações.

As variações mensais na quantidade de madeira transportada em relação à média são da ordem de $8 \%$. Entretanto, conforme mencionado anteriormente, das empresas estudadas apenas três apresentaram variações no número de caminhões contratados. Apesar de não ser possível alcançar conclusões mais consistentes devido ao pequeno número de observações, é interessante ressaltar que estas empresas (Empresa I, Empresa E e Empresa H) contratam transportadoras cujo número médio de caminhões é superior a $6(36,6$ e 12 , respectivamente), enquanto para as empresas que contratam pequenas transportadoras, como a Empresa $\mathrm{C}$ e a Empresa B, não existe oscilação no número de caminhões contratados.

Apesar do pequeno número de observações, é possível realizar algumas inferências a respeito 
Tabela 8 - Caracterização da especificidade de ativo físico. Fonte: dados da pesquisa.

\begin{tabular}{lccccccccc}
\hline Empresa & I & H & E & A & C & G & F & D & B \\
\hline Numcam & 36,25 & 12,00 & 6,42 & 3,0 & 1,6 & 10,44 & 9,40 & 5,3 & 1,6 \\
Físico* & 1 & 1 & 1 & 1 & 1 & 0 & 0 & 0 & 0 \\
\hline & $* 1$ - a transportadora presta serviços para outras empresas florestais; & 0 - a transportadora não presta serviços para \\
outras empresas florestais
\end{tabular}

Tabela 9 - Caracterização da variação do número de caminhões contratados. Fonte: dados da pesquisa.

\begin{tabular}{lccccccccc}
\hline \multicolumn{1}{c}{ Empresa } & I & H & E & A & C & G & F & D & B \\
\hline Numcam & 36,25 & 12,00 & 6,42 & 3,0 & 1,6 & 10,44 & 9,40 & 5,3 & 1,6 \\
Físico $^{*}$ & 1 & 1 & 1 & 1 & 1 & 0 & 0 & 0 & 0 \\
Oscilação $^{* *}$ & $20 \%$ & $10 \%$ & $19 \%$ & $0 \%$ & $0 \%$ & $0 \%$ & $0 \%$ & $0 \%$ & $0 \%$ \\
\hline
\end{tabular}

* 1 - a transportadora presta serviços para outras empresas florestais; 0 - a transportadora não presta serviços para outras empresas florestais

** Variação máxima do número de caminhões contratados em um ano

da influência de transportadoras de tamanhos distintos sobre as alterações no número de caminhões contratados. Tomando como exemplos as empresas Empresa I e a Empresa C, dois casos extremos em relação ao tamanho de transportadoras contratadas, e supondo que as alterações no tamanho total da frota sejam proporcionais ao volume de madeira transportada, a variação média ocorrida entre janeiro e abril de 1997 implicaria variações na frota de 10 e 5 caminhões, respectivamente. Considerando esta variação, o menor fornecedor de serviços de transporte da Empresa I passaria a trabalhar com 18 caminhões, ao invés de 20, o que representa uma redução de $10 \%$ no número de caminhões contratados desta transportadora específica. Já para a Empresa $\mathrm{C}$, a redução do número de caminhões contratados representaria o rompimento de contrato com 5 caminhoneiros autônomos.

Considerando a necessidade de manter-se relacionamentos de longo prazo, devido à existência de certas especificidades já comentadas anteriormente, é esperado que ao evitar rompimentos de contrato, as empresas produto- ras de celulose que trabalham com caminhoneiros autônomos tenham maiores dificuldades em ajustar de forma eficiente a oferta e a demanda por serviços de transporte.

\section{Conclusões}

$\mathrm{O}$ estudo das instituições que regem a transação de transporte de madeira entre florestas e fábricas de celulose foi feito num momento propício, em que a indústria, apesar da tendência à terceirização total do transporte, apresentava linhas de ação distintas no que se diz respeito à coordenação vertical desta transação. Apesar das diferentes estratégias de coordenação, uma característica marcante desta indústria é a similaridade dos processos industriais que estão a jusante e a montante da atividade do transporte de madeira. Estes dois fatores sugeriram que o estudo comparativo dos diferentes arranjos institucionais presentes na coordenação desta transação era analiticamente tratável.

Os resultados dos testes estatísticos não corroboraram o pressuposto de que níveis relativamente maiores de especificidade e incerteza 
estariam associados a maiores proporções de integração vertical parcial. Não foi possível verificar correlação entre as variáveis proxy escolhidas para medir as dimensões da transação e escolha por integrar-se verticalmente ou contratar serviços de terceiros.

Assim sendo, a manutenção de frotas parcialmente integradas por parte de algumas companhias produtoras de celulose, contrariando a tendência mais geral de terceirização total, está relacionada com a busca por uma melhor posição no processo de barganha e não necessariamente à economia em custos de transação.

A estratégia descrita anteriormente não explica totalmente o processo de escolha do tamanho da transportadora a ser contratada, haja visto que mesmo dentre as empresas com frotas totalmente terceirizadas existe variação no tamanho das transportadoras contratadas. Buscou-se então, nas variáveis proxy que medem as dimensões da transação, explicações para o tamanho das empresas contratadas.

Os resultados obtidos na busca por explicações para o tamanho das empresas contratadas foram compatíveis com o pressuposto de que altos níveis de especificidade estariam associados à contratação de grandes transportadoras. $\mathrm{Da}$ mesma forma, observou-se que a contratação de pequenas transportadoras ou caminhoneiros autônomos está associada a baixos níveis de especificidades; todavia, a contratação de transportadoras maiores não é restrita a transações com altos valores de especificidade.

Verificou-se que a variável que mede a especificidade de ativos dedicados, assim como a variável que mede a especificidade temporal, mostraram-se altamente correlacionadas com a escolha do tamanho da transportadora a ser contratada, refletindo a importância dos mercados regionais sobre esta opção.

Os resultados obtidos permitem inferir que a principal questão a ser considerada na definição do tamanho da transportadora a ser contratada é a oferta regional de serviços de transporte, pois esta oferta implica a magnitude dos custos associados a uma possível quebra contratual. Caso tais custos sejam relativamente altos para a companhia de celulose, espera-se que a existência de investimentos específicos para a transação, por parte da transportadora, mantenha o grau de dependência entre as empresas equilibrado, reduzindo os riscos de quebras contratuais para ambas as partes.

A mesma linha de raciocínio é válida caso o tomador de decisão seja a empresa transportadora. Uma forma de reduzir os riscos inerentes à existência de investimentos específicos para uma transação é a existência de reciprocidade em relação a estes riscos, ou seja, eles devem ser proporcionais aos riscos de desabastecimento que a companhia de celulose enfrenta. Assim como no caso anterior, tais riscos podem ser avaliados pelo nível de oferta regional de serviços de transporte.

A principal limitação desta pesquisa diz respeito às análises estatísticas realizadas. Tais dificuldades eram esperadas desde o início dos trabalhos, já que as pesquisas empíricas são um dos maiores desafios na agenda de pesquisas da ECT. A limitação imposta às análises estatísticas vieram principalmente do pequeno número de empresas existentes nesta indústria, o que restringe o número de ferramentas de análise a serem utilizadas. Dentre os problemas enfrentados, a impossibilidade de se fazer a estimação conjunta dos parâmetros foi o que mais prejudicou a análise do grau de terceirização.

Apesar das limitações existentes, este trabalho traz contribuições importantes no que diz respeito à recomendação de formas de mensuração das variáveis utilizadas pela ECT, possibilitando a análise de diversos aspectos dos arranjos institucionais vigentes, incluindo a questão relativa à integração vertical. 


\title{
Referências Bibliográficas
}

ANFPC - Associação Nacional dos Fabricantes de Papel e Celulose: "Relatório estatístico." São Paulo, 1995.

AZEVEDO, P.F.: Integração vertical e barganha. Tese (Doutorado) - Faculdade de Economia e Administração, USP, São Paulo, 1996.

JOSKOW, L.: “Contract duration and relationshipspecific investiments: empirical evidence from coal markets". The American Economic Review, v.77, n.1, p.168-185, 1987.

MAHONEY, J.T. et al.: "Spot markets, vertical contracting and vertical financial ownership: competition among organizational forms". Apresentado à conferência The conference interactions between public policies and private strategies in the food industries, Montreal. 1994.
MASTEN, S.E.: "Empirical research in transactioncost economics: challenges, progress, directions". Apresentado à conferência Transaction cost economics and beyond, Rotterdam, 1994.

SIEGEL, S.: Nonparametric statistics: for the behavioral sciences. Tokyo, McGraw-Hill, 1956.

WILLIAMSON, O.E.: “Comparative economic organization: the analysis of discrete structural alternatives". Administrative Science Quarterly, v.36, p.269-296, 1991.

\section{WOOD TRANSPORT VERTICAL COORDINATION: AN EMPIRICAL ANALYSIS OF THE BRAZILIAN PULP INDUSTRY INSTITUTIONAL ARRANGEMENT}

\begin{abstract}
This paper presents an analysis of the elements that influence the decision process of distinct institutional arrangements for the wood transport between forest and pulp industries. It aimed, through statistical analysis, at detecting the influence of the variables described in the TransactionCost Economics (TCE) for the decision process of institutional arrangements. The discussion includes not only vertical integration aspects, but those regarding the size of the carriers involved in the transactions.
\end{abstract}

Key words: vertical integration, transaction costs, pulp industries, wood transport. 